\title{
Staging Gastric Cancer Patients after Complete Surgical Resection: Which System Should We Use?
}

\author{
Sam S. Yoon, MD \\ Division of Surgical Oncology, Department of Surgery, Massachusetts General Hospital, \\ Harvard Medical School, Boston, MA
}

The most commonly used staging system for gastric adenocarcinoma is the American Joint Committee on Cancer (AJCC) tumor, node, metastasis (TNM) staging system. The 20107 th edition of the AJCC system made several changes from the 6 th edition, including redefining $\mathrm{T}$ and $\mathrm{N}$ categories and moving the staging of proximal gastric tumors within $5 \mathrm{~cm}$ of the gastroesophageal junction to the esophageal cancer staging system. ${ }^{1,2}$ TNM stage grouping were also redefined, with stage II further divided into IIA and IIB and stage IIIA and IIIB further divided into IIIA, IIIB, and IIIC. Since the publication of the 7th edition AJCC staging system in 2010, several single and multi-institution studies have compared the 6th and 7 th editions. Some studies have found the 7 th edition to be superior. $^{3-9}$ Other studies have found the 7 th edition to be either inferior to or no better than the 6th edition. ${ }^{10-12}$ Two studies from the same institution found opposing results. ${ }^{13,14}$ All these studies vary in the sort of patients examined, the extent of surgery and pathological analysis, and the methods of data analysis.

In this issue of Annals of Surgical Oncology, Dikken et al. compare disease-specific survival predictions for patients with gastric adenocarcinoma using the 6 th and 7 th editions of the AJCC staging system. ${ }^{15}$ Patients underwent surgery either at Memorial Sloan-Kettering Cancer Center (MSKCC) in New York or at one of several institutions in the Netherlands as part of the Dutch Gastric Cancer Trial

(C) Society of Surgical Oncology 2012

Published Online: 23 May 2012

S. S. Yoon, MD

e-mail: syoon@partners.org
(DGCT). ${ }^{16}$ In this group of 2,196 patients, the authors find that the predictive accuracy of the 7 th edition $\mathrm{N}$ categories is improved based on concordance measurements, but the predictive accuracy of the 7 th edition TNM stages is decreased. Survivals using the AJCC 6th edition did not significantly differ for two of the six stage groups, while survivals using the 7 th edition did not significantly differ for three of the seven stage groups. Thus, the authors conclude the AJCC 7th edition staging system has increased complexity with no improvement in predictive accuracy.

Dikken et al. put together a large cohort of Western patients treated with relatively extensive lymphadenectomies and perform a thorough comparison of the 6th and 7th AJCC staging systems. One primary advantage of this study is the use of data from several institutions in two different countries. Most previous studies on this topic are from Asian countries, so this multi-institution study of Western patients is important in determining whether we are making progress with the AJCC staging system revisions. However, as with most studies of this nature, there are several potential problems. First, the extent of lymphadenectomy for this cohort of patients varied, which causes problems with stage migration. At MSKCC, "most patients underwent a D2 lymph node dissection" and DGCT patients were randomized to D1 versus D2 node dissection. ${ }^{16}$ Furthermore, 22-28\% of patients in this study had $<15$ nodes examined, and the AJCC staging system suggests "that at least 16 regional nodes be assessed pathologically." 2 Second, the varying extent of lymphadenectomy and adjuvant therapies for patients in this study may have affected pathological staging and survival. Sixteen percent of MSKCC patients received neoadjuvant chemotherapy, which can result in downstaging the $\mathrm{T}$ and/or $\mathrm{N}$ stages. ${ }^{17}$ The 15 -years follow-up from the Dutch trial now demonstrates a significant $12 \%$ 
difference in gastric cancer-related death in the D1 versus D2 groups. $^{18}$ Some of the MSKCC patients received adjuvant therapy while none of the DGCT patients received adjuvant therapy. The Medical Research Council Adjuvant Gastric Cancer Infusional Chemotherapy (MAGIC) and the Intergroup 0116 trials showed a survival benefit for perioperative chemotherapy or postoperative chemoradiation at $3-5$ years of $9-13 \% .{ }^{17,19}$ Thus, the analysis by Dikken et al. may have come to different conclusions if all patients had had D2 node dissections, if all patients had had at least 15 nodes examined, if downstaging from neoadjuvant therapy was considered, or if the therapeutic effect of more extensive nodal dissection or adjuvant therapy was considered.

There are several additional important points that should be made regarding the staging of patients with gastric adenocarcinoma. First of all, accurate preoperative staging of patients with gastric adenocarcinoma is important, especially for patients with early tumors or with possible occult metastatic disease. There is a subgroup of patients with T1 tumors invading the lamina propria or the superficial submucosa whose tumors can be reliably removed endoscopically using endomucosal resection or endoscopic submucosal dissection. ${ }^{20}$ There is also a subgroup of patients with radiologically occult metastatic disease that can have metastatic disease detected by diagnostic laparoscopy with peritoneal washings. These patients have stage IV disease and likely do not benefit from surgical resection. ${ }^{21}$ Second, for gastric cancer patients undergoing potentially curative surgical resection, node status is likely the most important determinant of survival, and thus an adequate lymphadenectomy is essential for accurate staging. The standard lymphadenectomy in Japan and Korea, two-high incidence countries, for anything beyond a T1 tumor is a D2 lymphadenectomy, and the median number of examined nodes approaches $30 .^{22}$ In contrast, the United States has a very low incidence of gastric cancer, and $80 \%$ gastric cancer surgeries in the United States are performed at nonreferral centers that perform fewer than 15-20 cases per year. ${ }^{23,24}$ In the United States Intergroup 0116 trial where patients were randomized after gastric cancer surgery to no further therapy or to chemoradiation, more than $50 \%$ of patients received less than a D1 lymphadenectomy. ${ }^{19}$ Our analysis of the Surveillance, Epidemiology and End Results (SEER) database found that the median number of examined nodes was $10-11 .{ }^{25}$ Because of inadequate lymphadenectomies, the 7th AJCC staging system misclassifies over half of SEER patients. ${ }^{25}$ The use of node ratio (i.e., the number of positive nodes divided by the number of examined nodes) may be a better alternative to the absolute number of positive nodes when staging gastric cancer patients with few examined nodes. ${ }^{26}$ However, this alternative cannot completely correct for inadequate lymphadenectomy. ${ }^{25,27}$ Last, there are several alternatives to TNM-based staging systems, and the use of nomograms may more accurately assess survival for a particular patient, given that nomograms incorporate factors beyond tumor invasion, number of positive nodes, and presence of metastases. The MSKCC group has developed a nomogram that incorporates other known prognostic factors, including age, sex, tumor size, site of primary tumor, and Lauren histotype, and their nomogram has been validated at other Western institutions. ${ }^{28}$

Galileo said, "Measure what is measurable, and make measurable what is not so." The calculation of survival for gastric cancer patients continues to move from the immeasurable to the measurable. Whether the 7th edition of AJCC staging system for gastric adenocarcinoma makes progress toward more accurate measurement is clearly a matter of debate, but no system is perfect, and the trajectory of disease in afflicted humans is far more difficult to predict than the trajectory of planets.

\section{REFERENCES}

1. Stomach, Chapter 10. In: Greene FL, Page DL, Fleming ID, Fritz AG, Balch CM, Haller DG, Morrow $\mathrm{M}$, eds. AJCC cancer staging manual. 6th ed. New York: Springer; 2002. p. $99-106$.

2. Stomach, Chapter 11. In: Edge SB, Byrd DR, Compton CC, Fritz AG, Greene FL, Trotti A, eds. AJCC cancer staging manual. 7th ed. New York: Springer; 2010. p. 117-26.

3. Sun Z, Wang ZN, Zhu Z, Xu YY, Xu Y, Huang BJ, et al. Evaluation of the seventh edition of American Joint Committee on Cancer TNM staging system for gastric cancer: results from a Chinese monoinstitutional study. Ann Surg Oncol. In press.

4. McGhan LJ, Pockaj BA, Gray RJ, Bagaria SP, Wasif N. Validation of the updated 7th edition AJCC TNM staging criteria for gastric adenocarcinoma. J Gastrointest Surg. 2012;16:53-61.

5. Fang WL, Huang KH, Chen JH, Lo SS, Hsieh MC, Shen KH, et al. Comparison of the survival difference between AJCC 6th and 7 th editions for gastric cancer patients. World J Surg. 2011;35:2723-9.

6. Chae S, Lee A, Lee JH. The effectiveness of the new (7th) UICC $\mathrm{N}$ classification in the prognosis evaluation of gastric cancer patients: a comparative study between the 5th/6th and 7th UICC N classification. Gastric Cancer. 2011;14:166-71.

7. Kim DH, Oh CA, Oh SJ, Choi MG, Noh JH, Sohn TS, et al. Validation of seventh edition AJCC gastric cancer staging modifications. J Surg Oncol. 2012;105:26-30.

8. Jung H, Lee HH, Song KY, Jeon HM, Park CH. Validation of the seventh edition of the American Joint Committee on Cancer TNM staging system for gastric cancer. Cancer. In press.

9. Ahn HS, Lee HJ, Hahn S, Kim WH, Lee KU, Sano T, et al. Evaluation of the seventh American Joint Committee on Cancer/ International Union Against Cancer Classification of gastric adenocarcinoma in comparison with the sixth classification. Cancer. 2010;116:5592-8.

10. Kim SS, Choi BY, Seo SI, Jung MY, Choi HS, Ahn SM, et al. [The comparison between 6th and 7th International Union against Cancer/American Joint Committee on Cancer classification for survival prognosis of gastric cancer]. Korean J Gastroenterol. 2011;58:258-63. 
11. Kikuchi S, Futawatari N, Sakuramoto S, Katada N, Yamashita K, Shibata $T$, et al. Comparison of staging between the old (6th edition) and new (7th edition) TNM classifications in advanced gastric cancer. Anticancer Res. 2011;31:2361-5.

12. Yoon HM, Ryu KW, Nam BH, Cho SJ, Park SR, Lee JY, et al. Is the new seventh AJCC/UICC staging system appropriate for patients with gastric cancer? J Am Coll Surg. 2012;214:88-96.

13. Wang W, Sun XW, Li CF, Lv L, Li YF, Chen YB, et al. Comparison of the 6th and 7th editions of the UICC TNM staging system for gastric cancer: results of a Chinese single-institution study of 1,503 patients. Ann Surg Oncol. 2011;18:1060-7.

14. Qiu MZ, Wang ZQ, Zhang DS, Liu Q, Luo HY, Zhou ZW, et al. Comparison of 6th and 7th AJCC TNM staging classification for carcinoma of the stomach in China. Ann Surg Oncol. 2011; 18:1869-76.

15. Dikken JL, van de Velde CJH, Gonen M, Verheij M, Brennan MF, Coit DG. The new American Joint Committee on Cancer/ International Union Against Cancer staging system for adenocarcinoma of the stomach: increased complexity without clear improvement in predictive accuracy. Ann Surg Oncol. In press.

16. Bonenkamp JJ, Hermans J, Sasako M, van de Velde CJ, Welvaart $\mathrm{K}$, Songun I, et al. Extended lymph-node dissection for gastric cancer. N Engl J Med. 1999;340:908-14.

17. Cunningham D, Allum WH, Stenning SP, Thompson JN, van de Velde CJ, Nicolson M, et al. Perioperative chemotherapy versus surgery alone for resectable gastroesophageal cancer. $N$ Engl J Med. 2006;355:11-20.

18. Songun I, Putter H, Kranenbarg EM, Sasako M, van de Velde CJ. Surgical treatment of gastric cancer: 15 -year follow-up results of the randomised nationwide Dutch D1D2 trial. Lancet Oncol. 2010;11:439-49.

19. Macdonald JS, Smalley SR, Benedetti J, Hundahl SA, Estes NC, Stemmermann GN, et al. Chemoradiotherapy after surgery compared with surgery alone for adenocarcinoma of the stomach or gastroesophageal junction. N Engl J Med. 2001;345:725-30.

20. Japanese gastric cancer treatment guidelines 2010 (ver. 3). Gastric Cancer. 2011;14:113-23.

21. Maduekwe UN, Yoon SS. An evidence-based review of the surgical treatment of gastric adenocarcinoma. J Gastrointest Surg. 2011;15:730-41.

22. Park DJ, Lee HJ, Kim HH, Yang HK, Lee KU, Choe KJ. Predictors of operative morbidity and mortality in gastric cancer surgery. Br J Surg. 2005;92:1099-102.

23. Birkmeyer JD, Siewers AE, Finlayson EV, Stukel TA, Lucas FL, Batista I, et al. Hospital volume and surgical mortality in the United States. N Engl J Med. 2002;346:1128-37.

24. Smith DL, Elting LS, Learn PA, Raut CP, Mansfield PF. Factors influencing the volume-outcome relationship in gastrectomies: a population-based study. Ann Surg Oncol. 2007;14:1846-52.

25. Wang J, Dang P, Raut CP, Pandalai PK, Maduekwe UN, Rattner DW, et al. Comparison of a lymph node ratio-based staging system with the 7th AJCC system for gastric cancer: analysis of 18,043 patients from the SEER database. Ann Surg. 2012;255: 478-85.

26. Okusa T, Nakane Y, Boku T, Takada H, Yamamura M, Hioki K, et al. Quantitative analysis of nodal involvement with respect to survival rate after curative gastrectomy for carcinoma. Surg Gynecol Obstet. 1990;170:488-94.

27. Kong SH, Lee HJ, Ahn HS, Kim JW, Kim WH, Lee KU, et al. Stage migration effect on survival in gastric cancer surgery with extended lymphadenectomy: the reappraisal of positive lymph node ratio as a proper N-staging. Ann Surg. 2012;255:50-8.

28. Kattan MW, Karpeh MS, Mazumdar M, Brennan MF. Postoperative nomogram for disease-specific survival after an R0 resection for gastric carcinoma. J Clin Oncol. 2003;21:3647-50. 